
\title{
CIÊNCIANATURA
}

\section{Análise das adversidades climáticas na produção de tabaco na bacia hidrográfica do Alto Jacuí/RS}

Analysis of climate adversities in tobacco production in the Alto Jacuí/RS hydrographic basin

\author{
Vagner Apollo Duarte ${ }^{1}$ e Cássio Arthur Wollmann ${ }^{2}$
}

${ }^{1}$ Graduando em Geografia Bacharelado, Departamento de Geociências, Universidade federal de Santa Maria, Santa Maria/RS, Brasil

vagneraduarte@hotmail.com

${ }^{2}$ Professor Doutor, Departamento de Geociências, Universidade federal de Santa Maria, Santa Maria/RS, Brasil cassio_geo@yahoo.com.br

\section{Resumo}

O Rio Grande do Sul tem na agricultura um dos setores mais fortes de seu desenvolvimento, uma vez que, além da geração de renda e emprego, traz enorme retorno no valor agregado de receitas e divisas dos produtos exportados. Assim, estudar influencia climática no setor primário do tabaco. pode ajudar principalmente no planejamento de manejo mais adequado da cultura para produtores de tabaco aumentando assim, uma produção melhor e com mais qualidade e com isso, aumentar também o desenvolvimento econômico dos municípios produtores que fazem parte da bacia hidrográfica do Alto Jacuí. Entretanto, a cada ano ocorrem na produção agrícola gaúcha oscilações na produção e, um dos fatores de maior influência é o fator climático. Dessa forma o presente trabalho tem como objetivo analisar relação entre clima e produção de tabaco na Bacia Hidrográfica do Alto Jacuí/RS. Para a realização deste trabalho foi utilizado cartas sinóticas para analise das condições climáticas, aplicação de questionário a dois produtores de tabaco da região de estudo e também noticiários sobre adversidades climáticas na região. Os resultados foram bastante satisfatórios, pois foi possivel identificar a tamanha influencia que o clima exerce sobre a produção de tabaco na Bacia Hidrográfica do Alto Jacui/RS

Palavras-chave: Clima; Tabaco; Bacia Hidrográfica; Alto Jacuí.

\section{Abstract}

The Rio Grande do Sul has one of the strongest sectors of its development in agriculture, since, in addition to generating income and employment, it brings enormous returns in the added value of revenues and foreign exchange of exported products. Thus, studying the climatic influence in the primary tobacco sector can help in the planning of more appropriate management of the crop for tobacco growers, thus increasing better and better quality production and thus also increasing the economic development of the producing municipalities that make Part of the Alto Jacui river basin. However, oscillations in production occur every year in the agricultural production of Rio Grande do Sul, and one of the factors of greatest influence is the climatic factor. In this way, the present work aims to analyze the relationship between climate and tobacco production in the Alto Jacui-RS Hydrographic Basin. In order to carry out this work, we used synoptic charts to analyze climatic conditions, questionnaire application to two tobacco producers in the study region and also news reports on climatic adversities in the region. The results were quite satisfactory, since it was possible to identify the influence of climate on tobacco production in Alto Jacui-RS Hydrographic Basin.

Keywords: Climate; Tobacco; Hydrographic Basin; Alto Jacuí. 


\section{Introdução}

O Rio Grande do Sul tem na agricultura um dos setores mais fortes de seu desenvolvimento, uma vez que, além da geração de renda e emprego, traz enorme retorno no valor agregado de receitas e divisas dos produtos exportados. Entretanto, a cada ano ocorrem na produção agrícola gaúcha oscilações na produção e, um dos fatores de maior influência é também o climático.

Assim, a influência do clima na produção agrícola ocorre de maneira normal quando as chuvas precipitam conforme a necessidade da planta, mas de forma negativa quando as intempéries vêm por chuvas extremas, granizos, estiagens prolongadas e, até mesmo, na ocorrência de geadas muito fortes que habitualmente ocorrem no Estado. Diante destas adversidades, os efeitos climáticos provocam os mais variados problemas na produtividade agrícola, tanto na quantidade, como na qualidade. Isso acontece porque as práticas agrícolas são extremamente dependentes das variações climáticas.

Justamente pelo fato do Estado do Rio Grande do Sul possuir estações climáticas indefinidas, as repercussões dos elementos do clima desencadeados em diferentes tipos de tempo podem assumir papeis negativos em relação às culturas agrícolas, dado a sua variabilidade típica de climas subtropicais e, uma das culturas nas quais o clima tem enorme influência é a produção do tabaco. Assim, a fumicultura é uma atividade agrícola de grande importância para o Estado porque faz dele um dos maiores produtores nacionais junto com Santa Catarina e Paraná (SINDITABACO, 2015). O território compreendido pela bacia hidrográfica do Alto Jacuí abrange 42 municípios, sendo que 20 são produtores de tabaco além de outras culturas de subsistência.

Nesses municípios e na região a cada ano ocorrem de maneira intercalada vários casos de danos no cultivo em consequência de eventos extremos do clima. Dentre eles, as quedas de granizo, que geralmente arrasam as lavouras chegando a causar perda total, as estiagens, fenômeno climático causado pela insuficiência de precipitação pluviométrica numa determinada região por um período de tempo muito grande, ventanias e excesso de precipitação, são os eventos que causam a maior quebra na produção de tabaco.

Com isso, estudar influencia climática no setor primário do tabaco pode ajudar principalmente no planejamento de manejo mais adequado da cultura para produtores de tabaco aumentando assim uma produção melhor e com mais qualidade e com isso, aumentar também o desenvolvimento econômico dos municípios produtores que fazem parte da bacia hidrográfica do Alto Jacuí. Segundo (CUNHA 1997, p. 193) estes estudos "são particularmente úteis ao planejamento das atividades agrícolas e a formulação de política de desenvolvimento regional para o setor primário”.

Dessa forma, os estudos relacionados a influência climática sobre o cultivo do tabaco em uma região no qual tem alta produção é importante, pois, pode ajudar os produtores a mudarem as técnicas de manejo na lavoura ou tentar produzir outro tipo de produto que possa gerar uma renda extra, até por que, cada safra de tabaco que se inicia a perspectiva de uma boa safra depende muito do clima que em muitas vezes pode colaborar, assim, como poderá comprometer a safra.

Portanto, estes estudos podem muitas vezes alertar os produtores a fazerem o seguro optativo que todas as empresas oferecem aos seus produtores, basta o produtor pagar certa quantidade em dinheiro para contratar o seguro, sempre pode haver incertezas na safra e adversidades climáticas como, a precipitação excessiva, vendaval e granizo que podem gerar muitas perdas para os produtores e que ocorrem em todas as safras. Assim, este seguro agrícola é oferecido pela Associação dos Fumicultores do Brasil (AFUBRA), instituição representativa que dá apoio aos produtores e poder 
de negociação junto às indústrias beneficiadoras. Com isso, os produtores de tabaco conseguem no caso, diminuir um pouco os prejuízos, caso alguma adversidade climática atinja a produção.

\subsection{Caracterização geográfica da área de estudo}

A Bacia Hidrográfica do Alto Jacuí situa-se na porção centro-norte do Estado do Rio Grande do Sul, entre as coordenadas geográficas $28^{\circ} 08^{\prime}$ a $29^{\circ} 55^{\prime}$ de latitude Sul e $52^{\circ} 15^{\prime}$ a $53^{\circ} 50^{\prime}$ de longitude Oeste (figura 1).

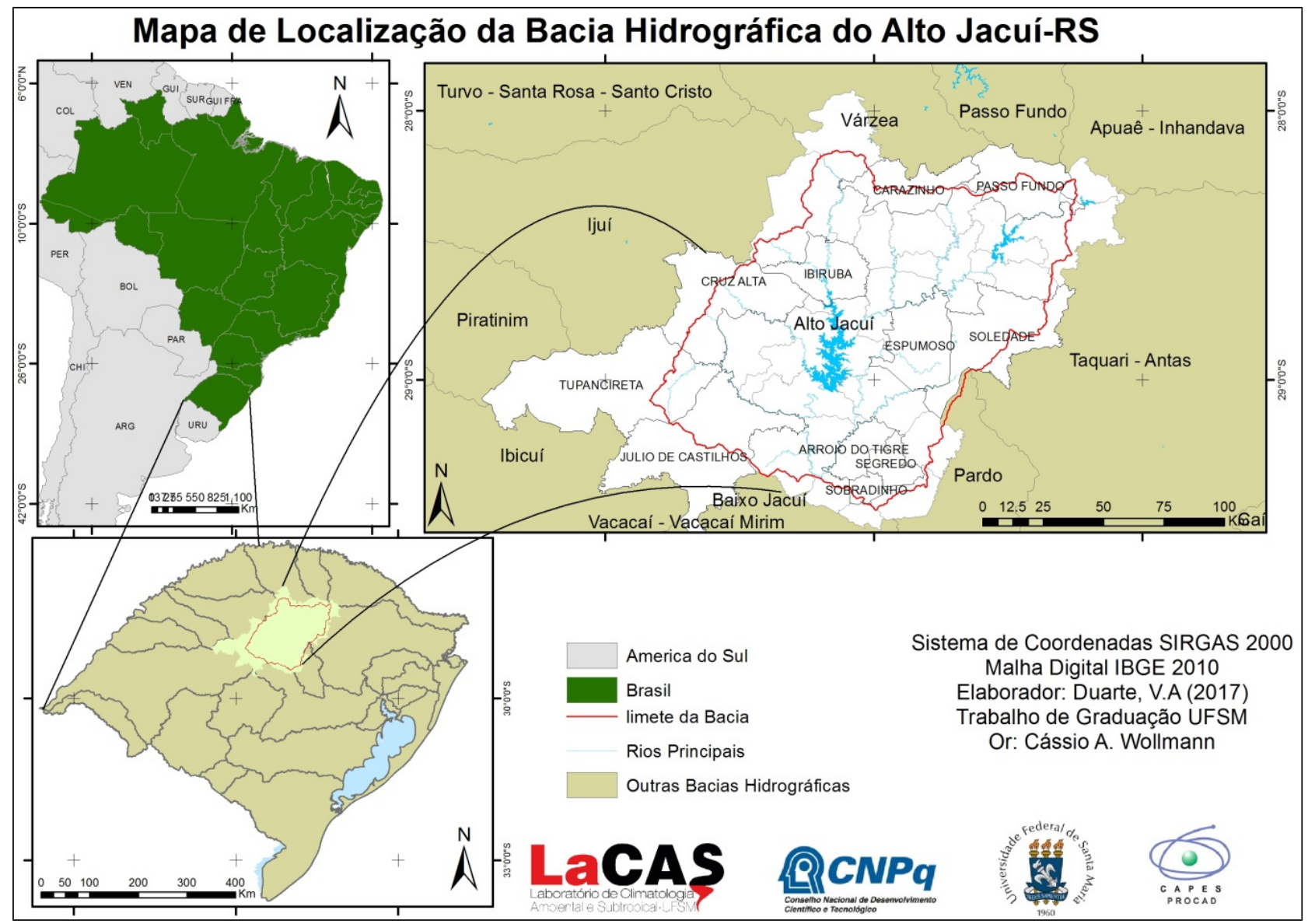

Figura 1: Localização da Bacia Hidrográfica do Alto Jacuí-RS.

A bacia abrange as províncias geomorfológicas Planalto Meridional e Depressão Central. Possui uma área de 12.985,44 km², com população estimada em 366.628 habitantes. Os principais cursos de água são os rios Jacuí, Jacuímirim, Jacuízinho, dos Caixões e Soturno. Os principais usos da água se destinam a irrigação, dessedentação animal e consumo humano (SEMA, 2015). Na área de estudo há uma formação geológica predominantemente de Rochas Vulcânicas e Arenitos intercalados da Formação Serra Geral. Na sua parte leste a um predomínio de rochas Vulcânicas Ácidas e Arenitos Intercalados e na parte oeste uma ocorrência de rochas Sedimentar da Formação Caturrita (CEEE, 2008). Em relação ao tipo de uso do solo a bacia hidrográfica é predominante para fins agrícolas, correspondendo a $64 \%$ da área total da bacia, o restante (36\%) se subdivide em floresta, solo exposto e corpos d'água. (ZIANI, 2014).

Esta região é caracterizada, principalmente, por relevos ondulados, apresentando algumas regiões montanhosas e outras mais planas, com colinas suaves, fornecendo a região distintas conformações. Em grande parte, apresentamse locais atípicos sob condições adversas à agricultura, de características ambientais restritas (alto relevo, declividade elevada, alta erosão do solo, baixa fertilidade, avanço das capoeiras, pedregosidade (lavouras com 
muitas pedras), pequena profundidade, acidez, etc.), dificultando ou impossibilitando, em certa medida, o uso de tecnologias agrícolas (trator, colheitadeira, entre outros). (REDIN, 2013, p.39).

Ainda salienta Redin (2013) que por outro lado, essa região contém áreas planas e férteis, alternando solos rasos e profundos, várzeas ou levemente onduladas traçando um espaço geográfico com distintas potencialidades agrícolas. Em todos os municípios envolvidos, a produção de tabaco está presente em maior ou menor expressividade guiando a renda agrícola de muitas propriedades rurais.

No Estado do Rio Grande do Sul, segundo a (AFUBRA, 2013/2014), são 274 municípios que produzem tabaco, sendo mais de 50\% dos municípios, ou seja, a produção de tabaco está distribuída no território gaúcho com maior concentração no vale do Rio Pardo e parte do Centro Serra. Dessa forma, grande quantidade de municípios produtores de tabaco está localizada dentro da bacia hidrográfica do Alto Jacuí, sendo 20 no total (Figura 2).

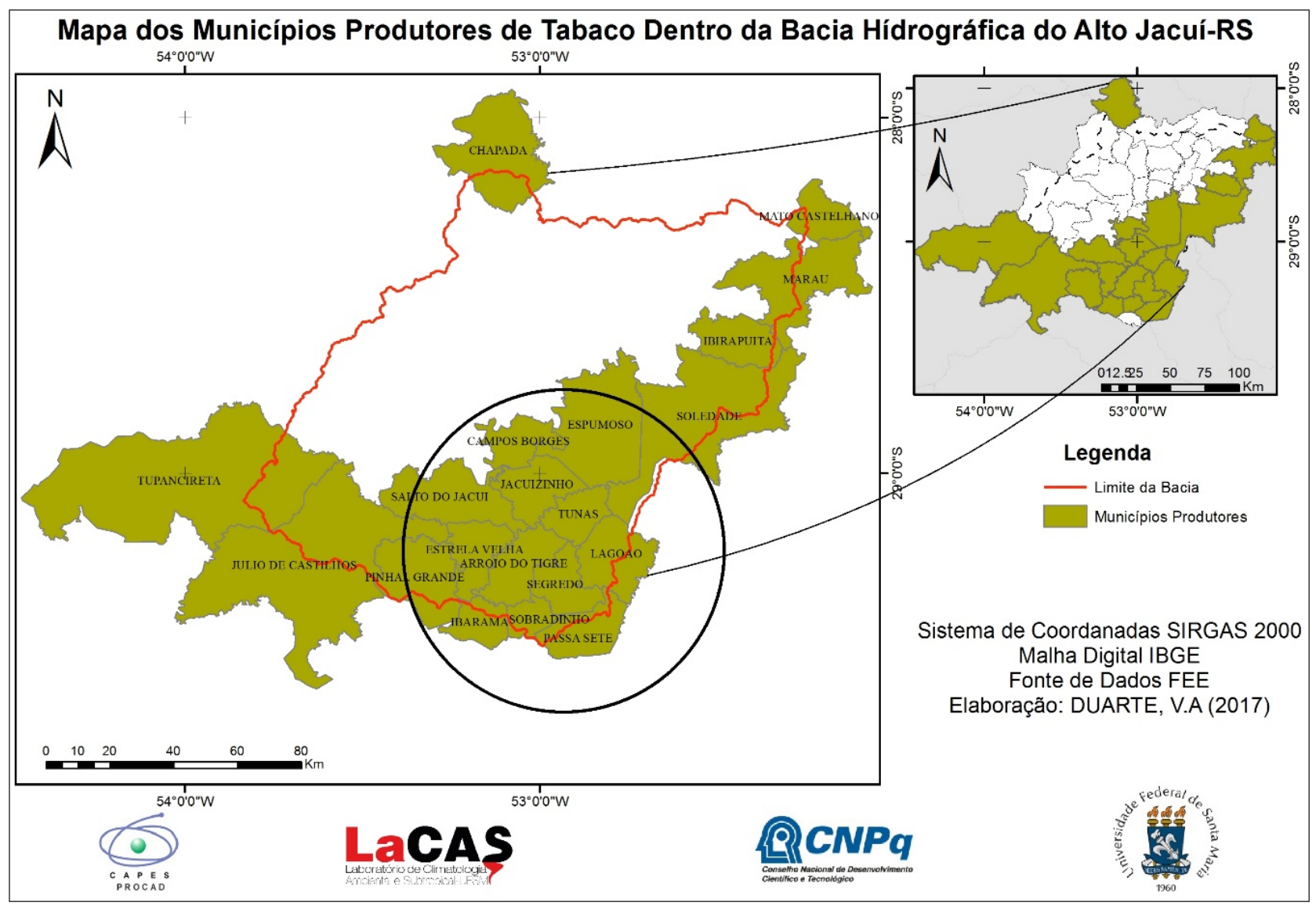

Figura 2. Mapa dos 20 municípios produtores de tabaco na Bacia Hidrográfica do Alto Jacuí-RS.

Neste contexto, na região o predomínio é da agricultura familiar, apesar da pequena lavoura plantada o cultivo representa 51,4\% da renda familiar dos agricultores dados da Associação dos Fumicultores do Brasil (AFUBRA).

Com relação ao tipo de uso do solo, a bacia hidrográfica é predominante para utilizada para fins agrícolas que corresponde a $64 \%$ da área total da bacia, o restante (36\%) se subdivide em floresta, solo exposto e corpos d'água (ZIANI, 2014). Portanto, nesta região predomina a agricultura familiar, sendo, pequenos municípios produtores. Portanto, como em todas as culturas os fatores naturais que interferem na produção agrícola são excepcionalmente o solo, clima, relevo, orientação de vertentes, entre outras. E, sem dúvida, o clima é o que exerce maior influência no 
desenvolvimento do tabaco, pois é uma cultura que assim como as outras é altamente dependente de fatores climáticos como temperatura, pluviosidade, umidade do solo, radiação solar etc.

\subsection{Objetivos}

Objetivo Geral:

$>$ Analisar as adversidades climáticas provocadas pelo clima na produção de tabaco na bacia hidrográfica do Alto Jacuí/RS;

Objetivos Específicos:

$>$ Verificar a repercussão da mídia com relatos da ocorrência de danos nas lavouras de tabaco por consequência de tempo severo em municípios da bacia hidrográfica do Alto Jacuí/RS;

$>$ Identificar e analisar o período do ano com maior ocorrência de granizo e outras adversidades climáticas que prejudicam a produção do tabaco, através da entrevista com uma meteorologista e relatos dos produtores.

\section{Revisão Bibliográfica}

\subsection{O clima do Rio Grande do Sul}

O clima do Rio Grande do Sul pode ser considerado bem caracterizado do ponto de vista de suas médias e normais climatológicas, e sendo um Estado no qual a sua economia baseia-se na produção agrícola, o clima torna-se fator essencial para uma boa produção. Dessa forma, (AYOADE, 2004, p. 232) considera que conforme o sistema internacional de classificação climática de Köppen, o Rio Grande do Sul se enquadra na zona fundamental temperada (c), tipo fundamental úmido (Cf), com duas variedades específicas: Subtropical (Cfa) e temperado (Cfb).

Os fatores geográficos como a orografia, continentalidade e a maritimidade são fatores que estão relacionados diretamente com a dinâmica da atmosfera. Com isso, (Cunha, 1997, p. 182) aborda que "as principais massas de ar que influenciam a na gênese do clima do sul do Brasil são: Massa tropical Marítima (Tm); Massa Polar Marítima (Pm); Massa Tropical Continental (Tc) e a Massa Equatorial Continental (Ec)”.

\footnotetext{
Como toda a Região Sul do Brasil, o território sul-rio-grandense situa-se em zona climaticamente de transição e, por isso, as principais características climáticas da área de estudo refletem a participação tanto dos Sistemas Atmosféricos Extratropicais (massas e frentes polares) quanto dos Intertropicais (massas tropicais e Correntes Perturbadas), embora os primeiros exerçam o controle dos tipos de tempo. Assim, a posição subtropical faz com que a região seja área de confronto periódico entre forças opostas, provocado pelo avanço sistemático dos Sistemas Atmosféricos de origem polar em direção aos polares tropicalizados (Massa Polar Velha - MPV) ou aos sistemas de origem tropical (Massa Tropical Atlântica ou Continental), proporcionando a distribuição das chuvas durante todo o ano, motivada pelas sucessivas passagens frontais, sem ocorrência de estação seca no regime pluviométrico. (SARTORI 2003, p. 29)
}

Portanto Sartori (2003) também destaca que os fatores dinâmicos é que determinam a gênese do clima de uma região e controlam a sucessão e a definição dos tipos de tempo, que pouca (ou quase nenhuma) interferência sofrem dos fatores geográficos regionais, representados principalmente pela altitude, relevo, continentalidade e vegetação, responsáveis apenas por variações dos valores dos elementos climáticos como temperatura, pressão atmosférica, vento, umidade, entre outros. 


\subsection{Fenologia da cultura}

Segundo (BOIEIRO, 2008) a planta do Nicotinana tabacum pode atingir dois metros de altura, e se encontra, coberta de pelos viscosos. Os caules apresentam-se eretos, robustos, cilíndricos e ramosos.As folhas são alternas, sésseis, ovais ou lanceoladas ponte agudas, inteiras, pegajosas, com nervuras muito salientes na página inferior e de cor verde mais carregado na página superior. As flores são grandes, rosadas, munidas de brácteas dispostas numa espécie de panícula na extremidade dos ramos, tendo cálice tubuloso, esverdeado. Finalmente, o fruto forma uma cápsula ovóide, encerrando numerosíssimas sementes muito pequenas, rugosas, irregularmente arredondadas.

A produção do tabaco passa por vários estágios até chegar ao seu destino final que é o cigarro. O tabaco passa por etapas de manejo, conforme orientações da Souza Cruz a produção de tabaco passa por cinco principais etapas importantes que são (figura 3).

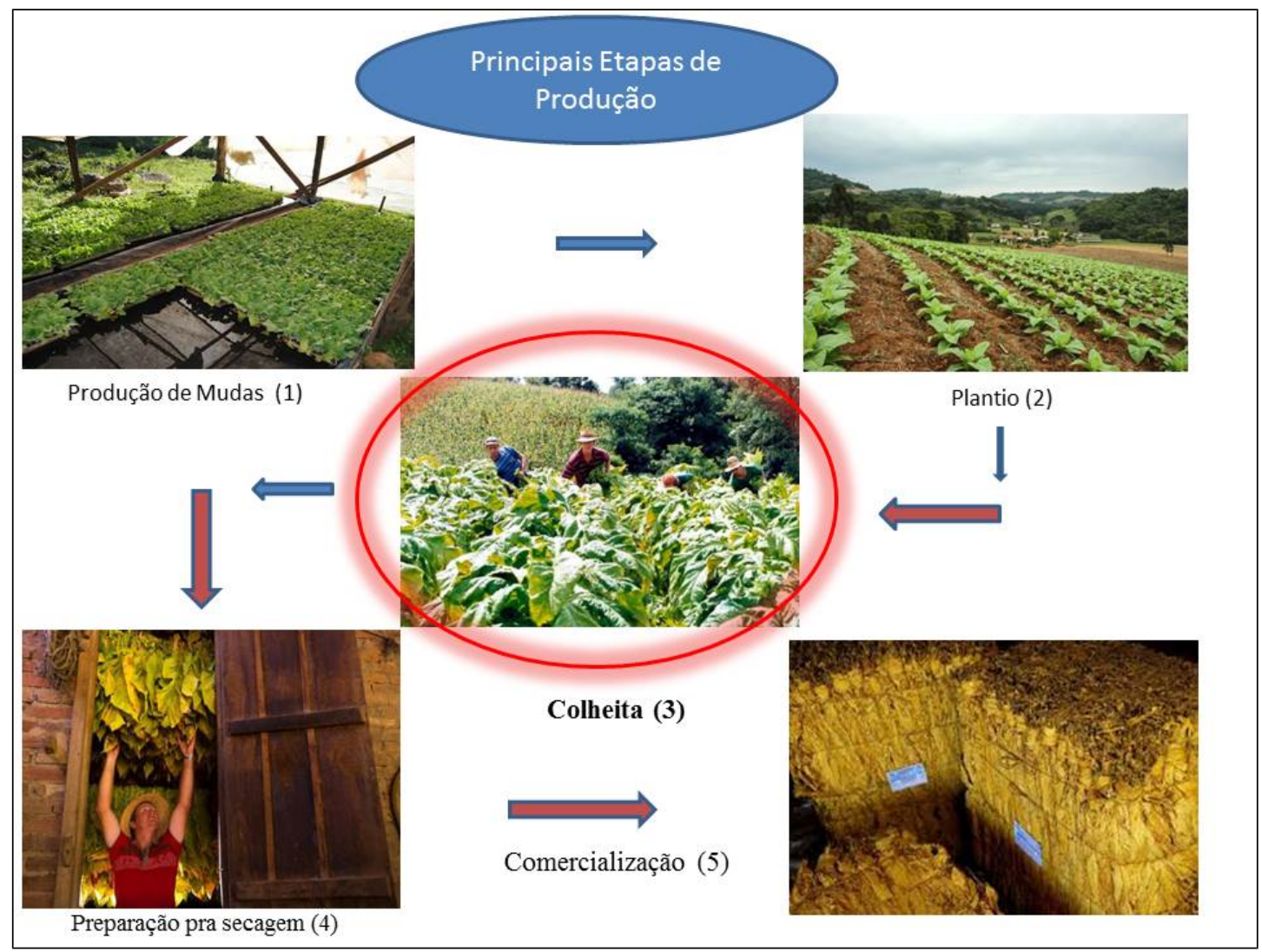

Figura 3. Ilustração das fases da produção do Tabaco.

Org. Duarte. V, A. 2017.

A imagem no meio da figura está mais destaca, pois é nessa fase que o clima tem a maior influencia sobre a produção do tabaco. Além do forte sol que pode comprometer a qualidade das folhas, as chuvas nesta época do ano são bastante perigosas em função do ar quente atuante sobre o Estado e que em muitos casos ocorrem chuvas com presença de granizo que pode comprometer a safra em função do tamanho em que se encontra a planta.

A fase de Canteiros que compreende a atividade de produção de mudas de fumo, que necessita da construção de canteiros ou viveiros, enchimento das bandejas com uma terra especial, semeação, aplicação de adubos para uma planta de boa qualidade, tratamentos preventivos e poda. (SOUZA CRUZ, 2017). 
A segunda é a fase da lavoura onde compreende o transplante das mudas para a lavoura definitiva (Plantio), e consiste dos seguintes passos: Preparação do solo; adubação de base; transplante das mudas; tratos culturais; adubação de cobertura; adubação de reposição (se necessário); controle de pragas e doenças. Aqui vale ressaltar a técnica de plantio amplamente divulgada e utilizada pelos produtores de fumo é o Plantio Direto, que dispensa a aração do solo, pois o plantio é feito diretamente sobre os restos de outras lavouras ou adubação verde semeada com antecedência. O plantio direto protege o solo, pois mantém uma camada de palha sobre o mesmo, favorecendo a produção de fumo fisicamente mais limpo (menos impurezas, tais como capim, areia e pó) e, ao longo do tempo, reduz a utilização de fertilizantes. (SOUZA CRUZ, 2010).

E a terceira fase de Capação e colheita que compreende a quebra da parte superior da planta (botão floral), e ocorre, em média, 70 dias após o transplante. Nesta fase o produtor efetua as seguintes ações: Capação (ato de quebrar a parte superior da planta); Controle de brotos, com aplicação de um produto anti-brotante. O objetivo da capação é evitar que os nutrientes absorvidos pela planta sejam enviados para a parte superior (flores e produção de sementes), mas que sejam utilizadas pelas folhas, fazendo com que estas se desenvolvam mais, com maior peso e qualidade. (Souza Cruz, 2017). Então, a colheita inicia-se quando o tabaco apresenta algumas características de maturação, como por exemplo, as folhas inferiores apresentam manchas amareladas como mostra a ilustração da planta do tabaco (figura 4).

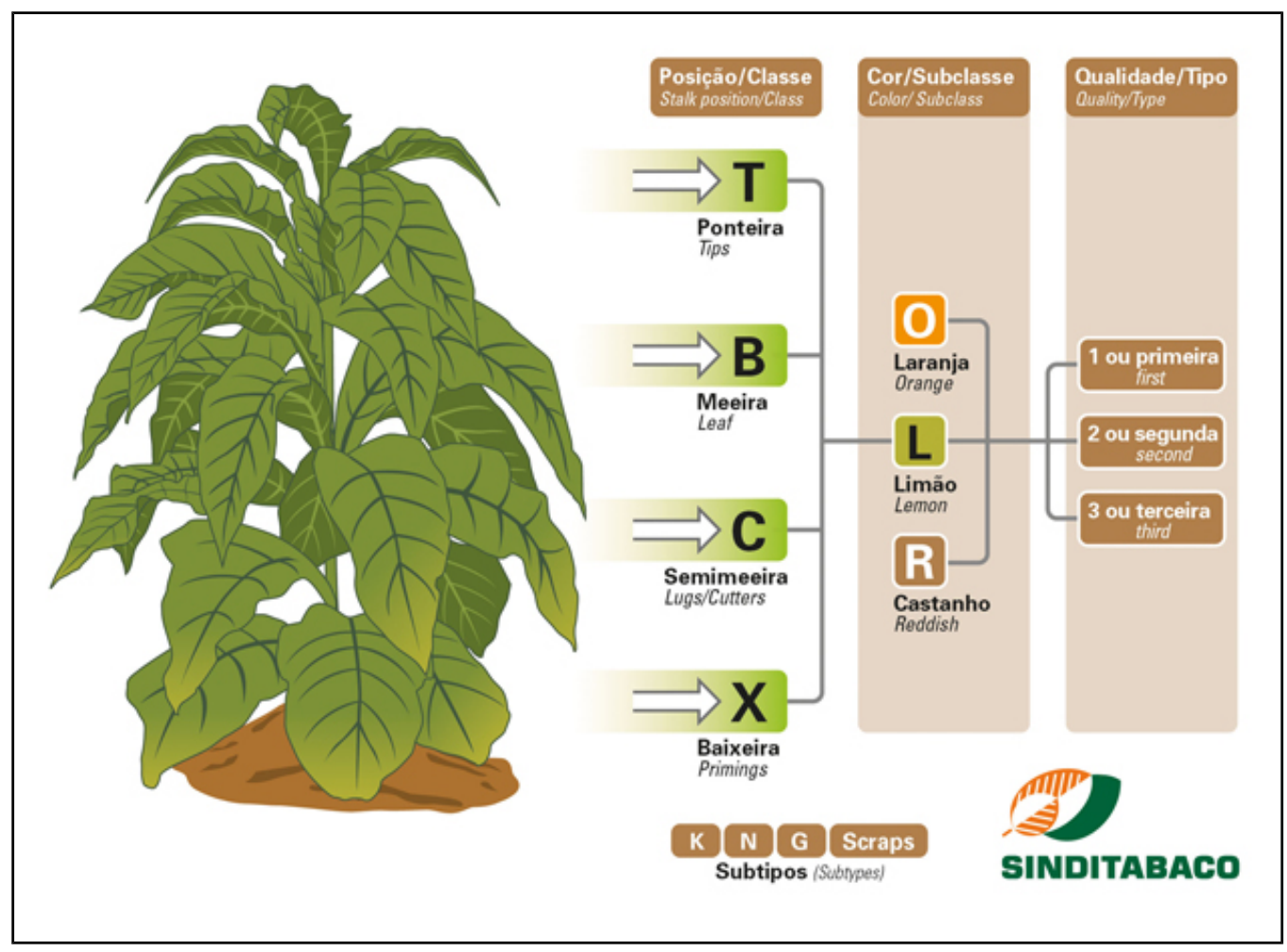

Figura 4 - Imagem do Tabaco pronto pra ser colhido. Fonte: Sinditabaco, 2017.

Assim, o talo fica esbranquiçado, perda de pilosidade, a folha se quebra fácil no caule, presença de manchas necróticas nas folhas e cor verde pálida. Conforme a Philip Morris International (2016) após a secagem as folhas são classificadas pelo produtor de acordo com a qualidade e posição no caule. As folhas são então empacotadas em fardos e estão prontas para serem transportadas. Os fardos de tabaco são transferidos para uma estação de compra para serem classificados e adquiridos subsequentemente pelos compradores de folha de Tabaco. 
$\mathrm{Na}$ quarta fase é a da cura ou secagem que consiste em promover importantes transformações físico-químicas nas folhas colhidas nas lavouras, seguido de uma lenta e controlada extração da água delas. Todo esse processo ocorre dentro de unidades de cura, também chamadas de estufas. Conforme indaga a (PROFIGEN, 2017) a cura do tabaco obrigatoriamente deve passar por todas as fases, desde a amarelação até a secagem do talo, respeitando o período de horas para cada fase para maximizar a qualidade do tabaco. Essas fases são:

\subsubsection{Amarelamento}

Esta fase também é chamada de finalização da maturação do tabaco em ambiente controlado, pois é quando as principais e mais desejáveis transformações, físico-químicas ocorrem. Nessa etapa as células das folhas continuam vivas. A cura do tabaco normalmente inicia com a temperatura ambiente. Quando esta estiver abaixo de $90^{\circ} \mathrm{F}$ deve-se fazer o aquecimento da estufa para atingi-la. Essa temperatura deverá ser mantida por aproximadamente 12 horas e a seguir elevada gradualmente, em média $2^{\circ} \mathrm{F}$ por hora, até chegar a $100^{\circ} \mathrm{F}$. (PROFIGEN, 2017).

\subsubsection{Murchamento}

Neste momento, aumenta-se a temperatura, lentamente, em torno de $1^{\circ} \mathrm{F}$ por hora, até atingir $105^{\circ} \mathrm{F}$ abrindo levemente os ventiladores inferiores, para permitir a entrada de ar que vai acelerar o processo de "amarelamento", além de promover o murchamento das folhas. Mantem-se em $105^{\circ} \mathrm{F}$ até que as folhas dos dois primeiros estaleiros estejam completamente amarelas e murchas. A partir desse momento pode-se aumentar a temperatura até $110^{\circ} \mathrm{F}$ até que a ponta das folhas comece a virar, é preciso manusear adequadamente a ventilação para manter o equilíbrio da temperatura e umidade de acordo com a tabela de cura. Nesse estágio o tabaco perdeu aproximadamente 20 a $30 \%$ da água. (PROFIGEN, 2017).

\subsubsection{Fixação da cor e secagem da lâmina}

Para fixar a cor do tabaco, a temperatura deve aumentada gradualmente de $2^{\circ} \mathrm{F}$ por hora até atingir $120^{\circ} \mathrm{F}$, sempre observando a relação bulbo seco e bulbo úmido conforme tabela de cura, adequando a abertura da ventilação inferior e superior. Essa temperatura deve permanecer até que o tabaco dos estaleiros superiores esteja completamente amarelo e murcho. (PROFIGEN, 2017).

\subsubsection{Secagem do talo}

Restando somente os talos para secar, a temperatura continua sendo aumentada até atingir $165^{\circ} \mathrm{F}$. Como há pouca umidade a extrair, as saídas naturais entre as telhas são suficientes para a exaustão lenta dessa umidade. Dessa forma, conforme orientação da Profigen, é indicado o seguinte tempo de secagem como esta especificado na tabela 1.

Tabela 1. Tempo de secagem do tabaco.

\begin{tabular}{l|c}
\hline \multicolumn{1}{c|}{ Tempo (horas) } & Objetivo \\
\hline $48-60$ & Amarelação \\
\hline $18-24$ & Murchamento \\
\hline $48-60$ & Secagem da lâmina \\
\hline 24 & Secagem do talo \\
\hline
\end{tabular}


Então, essa fase é muito importante e deve ser bastante cuidadosa, pois é aí que vai ser dada a qualidade do tabaco que depois será classificado conforme a sua cor. E a quinta fase, seria a classificação e comercialização do produto. O Tabaco em olha curado (seco) será classificado em grupos, subgrupos, classes, subclasses, tipos e subtipos, segundo o seu preparo, sua apresentação e arrumação, sua posição nas plantas, cor das folhas e sua qualidade.

\subsection{Clima x Fumicultura}

O clima tem seus pontos positivos e também os pontos negativos em relação á produção de tabaco. Os pontos positivos, são quando o clima colabora de maneira que faz com que a safra de tabaco seja cheia, com produto de boa qualidade e quantidade. Mas o que é bastante comum durante a produção são os pontos negativos (Figura 5).

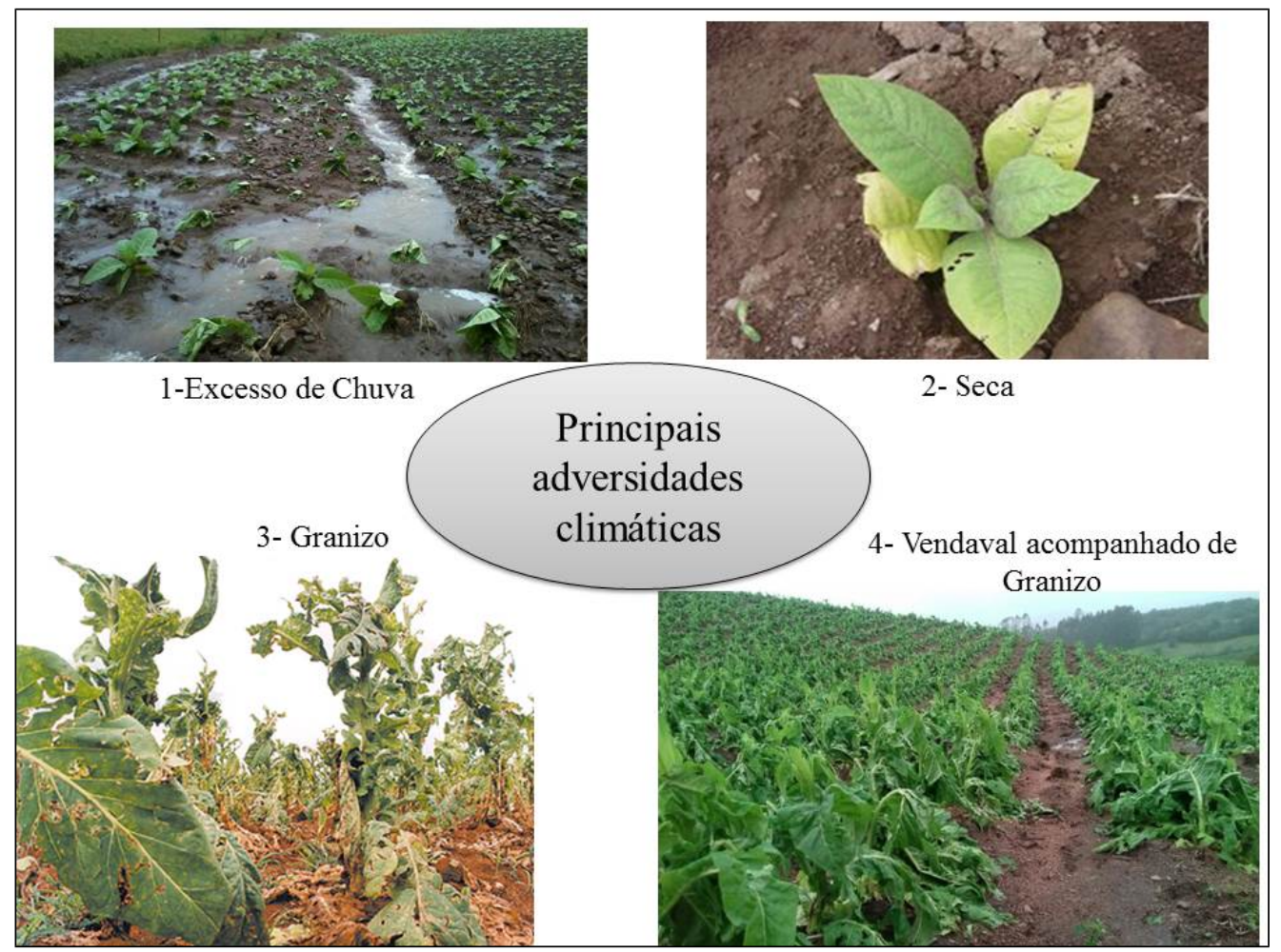

Figura 5 - Principais Adversidades Climáticas nas Lavouras de tabaco.

Org. Duarte. V, A. (2017).

Então, se tem como principais adversidades negativas o excesso de chuva (1) que provoca a erosão do solo das lavouras e é um dos problemas que assolam as propriedades rurais, causando sérios prejuízos, como a diminuição da produtividade, aumento do uso de fertilizantes, diminuição da capacidade de retenção da água no solo, contaminação dos corpos hídricos, dentre outros fatores. (ANTONELLI, 2010).

Outro caso bem comum que pode atrasar muitas vezes o desenvolvimento da planta é escassez de chuva(2). Caso fique muitos dias sem chuva e a planta se encontra no seu ciclo de desenvolvimento pode haver grande quebra na 
produção como: folhas pequenas e finas o que acarreta perdas no seu peso. Com o calor as plantas ficam desidratadas, resultado do sol forte em um período de mais de 10 dias sem chuva. Para os produtores, as folhas queimadas significam prejuízo, pois o fumo vai perder mais de $50 \%$ do valor na hora da comercialização em função de manchas e queimaduras que significa queda na qualidade Afubra (2013).

A causa que provoca os maiores prejuízos nas lavouras de tabaco é a chuva acompanhada de granizo (3), muitas vezes quando ocorre este fenômeno é de maneira bastante localizada, mas onde atinge geralmente os estragos são imensos. Neste caso, é o momento em que muitos produtores de tabaco acionam as fumageiras em função do seguro que as mesmas oferecem e um representante das fumageiras vão até as residências para fazer o levantamento das perdas.

Quando não bastasse uma chuva de granizo, em muitos casos os dois fenômenos ocorrem juntos, que é vendavais acompanhados de granizo (4). Neste evento, além de quebrar muito as folhas de tabaco ainda derrubam os pés da planta, em alguns casos pode não haver perda total, mas arrasa as lavouras onde atinge.

\section{Metodologia}

Para a realização deste trabalho, primeiramente foi feito algumas leituras sobre alguns assuntos relacionados com o clima e agricultura que está englobado mais especificamente na área da agroclimatologia. Foi possível buscar nos sites das próprias fumageiras, nos meios de comunicação muita informação sobre o tabaco o que auxiliou bastante para o desenvolvimento deste trabalho.

Portanto, a aquisição de noticiais sobre os estragos provocados em lavouras de tabaco na região de estudo foi coletado através de noticiários com divulgação, principalmente de rádios e jornais da região, como a Rádio Gazeta da Serra, uma rádio local situada no município de Sobradinho com filial em Arroio do Tigre,que também possui um jornal dessa empresa de telecomunicações e fez com que facilitasse essa busca pela informação e, ambos os municípios estão situados dentro da bacia hidrográfica do Alto Jacuí que é a área de estudo e são um dos principais municípios produtores de tabaco.

Ainda sobre a busca por informações, também foi encontrado alguns relatos notificados por outra rádio local que é a Jacuí FM e AM com sede em Sobradinho, na qual faz cobertura do noticiário de toda essa região do Alto Jacuí. Então, com isso, foi possível encontrar diversas notícias sobre os danos que o clima provoca sobre o tabaco na bacia hidrográfica do Alto Jacuí.

Conforme orientações de Wollmann (2011),foi aplicado um questionário de entrevistas com dois produtores de tabaco da região do Alto Jacuí, sendo um de linha Taquaral interior do município de Arroio do Tigre e o outro de Boa Esperança interior do município de Ibarama. Foi feito a aplicação desse questionário para saber os relatos desses produtores se caso já teriam vivenciados essas perdas em função de anomalias climáticas.

Para ajudar na identificação de períodos como um maior índice de chuvas com granizo foi realizado uma entrevista com a meteorologista Taciana Weber de Menezes que explicou um pouco sobre a formação do granizo, as condições de tempo mais propícias para a ocorrência deste fenômeno e também, as estações com uma maior probabilidade de granizo. As Perguntas foram:

- A agricultura no RS sofre bastante com fenômenos climáticos que são bastante decorrentes no ano. Muitas vezes os temporais veem acompanhados de granizo que é um dos principais eventos extremos que ocorrem no estado que é um dos mais prejudiciais para a agricultura. Dessa forma, por que o estado do RS tem tantas 
ocorrências de granizo e qual o(os) períodos (estações) do ano são mais propícios para a formação deste fenômeno?

- Pode-se afirmar que no período de transição do inverno para o verão há uma ocorrência mais significativa de eventos climáticos acompanhados de granizo?

- A formação de bolsões de calor nos vales podem contribuir para a formação de nuvens Cumulusnimbus?

Além disso, foram utilizadas duas cartas sinóticas de dois dias para auxiliar na identificação dos centros de ação que estavam predominando nos dias em que ocorreram esses incidentes climáticos em lavouras de tabaco da região.

\section{Discussão dos Resultados}

$\mathrm{O}$ aumento das ondas de calor no mundo se tem influência direta na atividade agrícola com crescimento do registro de secas intensas ou chuvas em excesso, temporais entre outros. E este aspecto é crítico porque a cultura, a planta em sí demora a se adaptar as diversas mudanças climáticas durante o seu ciclo de produção. O impacto muitas vezes é muito maior em função das ondas de calor do que em relação ao próprio aumento da temperatura, mesmo caso é o das chuvas, a quantidade de chuva em pouco tempo causa um impacto muito maior na produção de tabaco do que alguns dias consecutivos de chuvas menos intensas. Dessa forma, foram registrados dois casos relevantes na bacia hidrográfica do Alto Jacuí, e foram os seguintes:

4.1 Adversidade climática em 15 de Janeiro de 2017.

O primeiro caso ocorreu no dia 15 de janeiro de 2017, houve o registro de uma forte chuva de granizo que atingiu as lavouras de produtores de tabaco nos municípios de Arroio do Tigre e parte de Segredo. Conforme a divulgação da Rádio Jacuí FM e AM, aproximadamente 200 produtores de tabaco acionaram o seguro da AFUBRA até á tarde de quarta-feira (19) em função do temporal de domingo (15) à noite na região Centro Serra e causou grandes estragos nas lavouras de alguns produtores, como mostra a foto da lavoura de um produtor (Figura 6).

A lavoura atingida na foto é a do produtor João Paulo Porscher, ele salientou na entrevista que em alguns locais houve perda total do tabaco. O granizo foi muito localizado e algumas lavouras de tabaco, distante a apenas 100 metros de uma e outra que foram atingidas, nada sofreram. A demora ao acionar o seguro se deve ao sinal de telefonia móvel também afetado. Segundo João Paulo, o período em que mais se nota prejuízos com temporais, no sul do país, é de outubro até a metade de fevereiro, quando a maioria dos produtores já colheu todo o tabaco.

Dessa forma, pela analise sinótica e das imagens de satélite do CPTEC/INPE do dia 15 de janeiro, o que proporcionou este evento foi o sistema de baixa pressão vinda do Chaco, conhecida também como (baixa do Chaco ou Massa Tropical Continental). Na figura 7 é possível visualizar a condição atmosférica no momento do evento. 


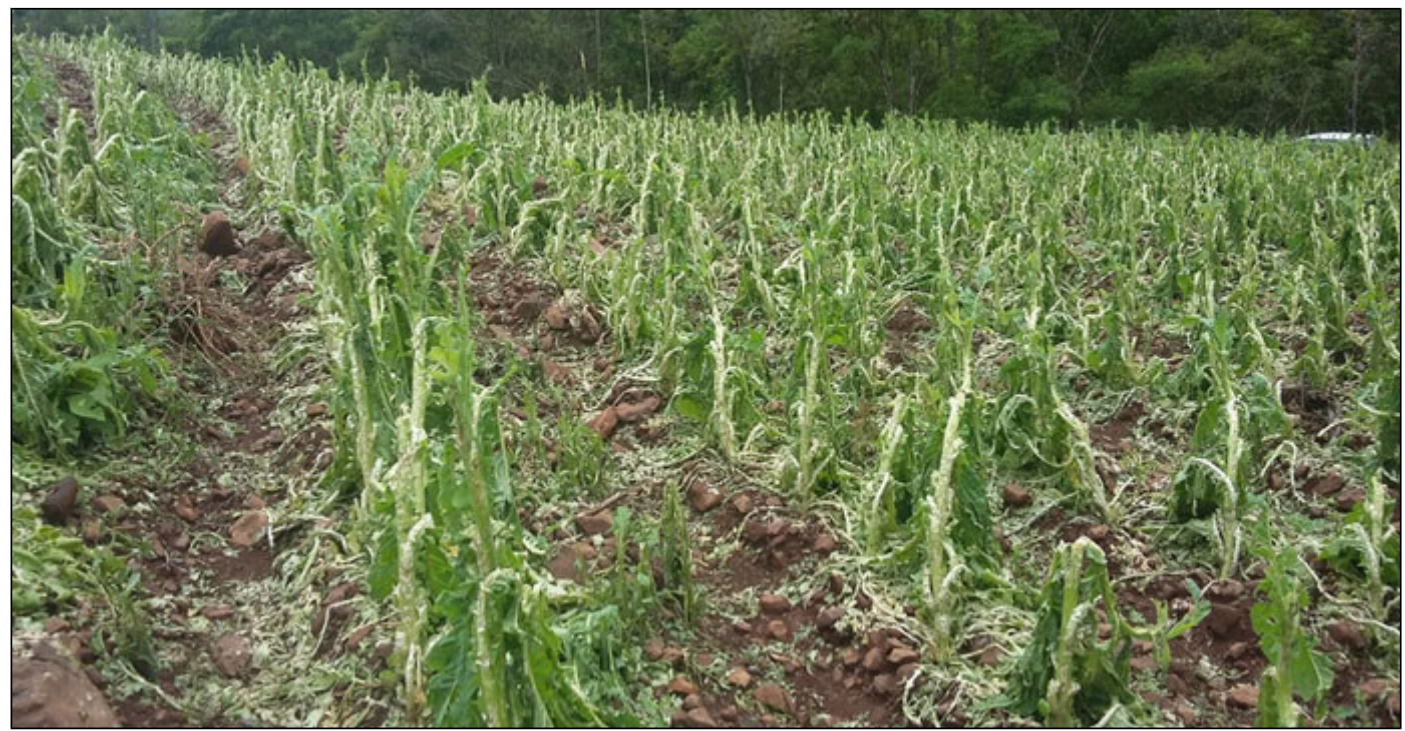

Figura 6 - Lavoura tingida pelo granizo. Por: Ivanio Melchior

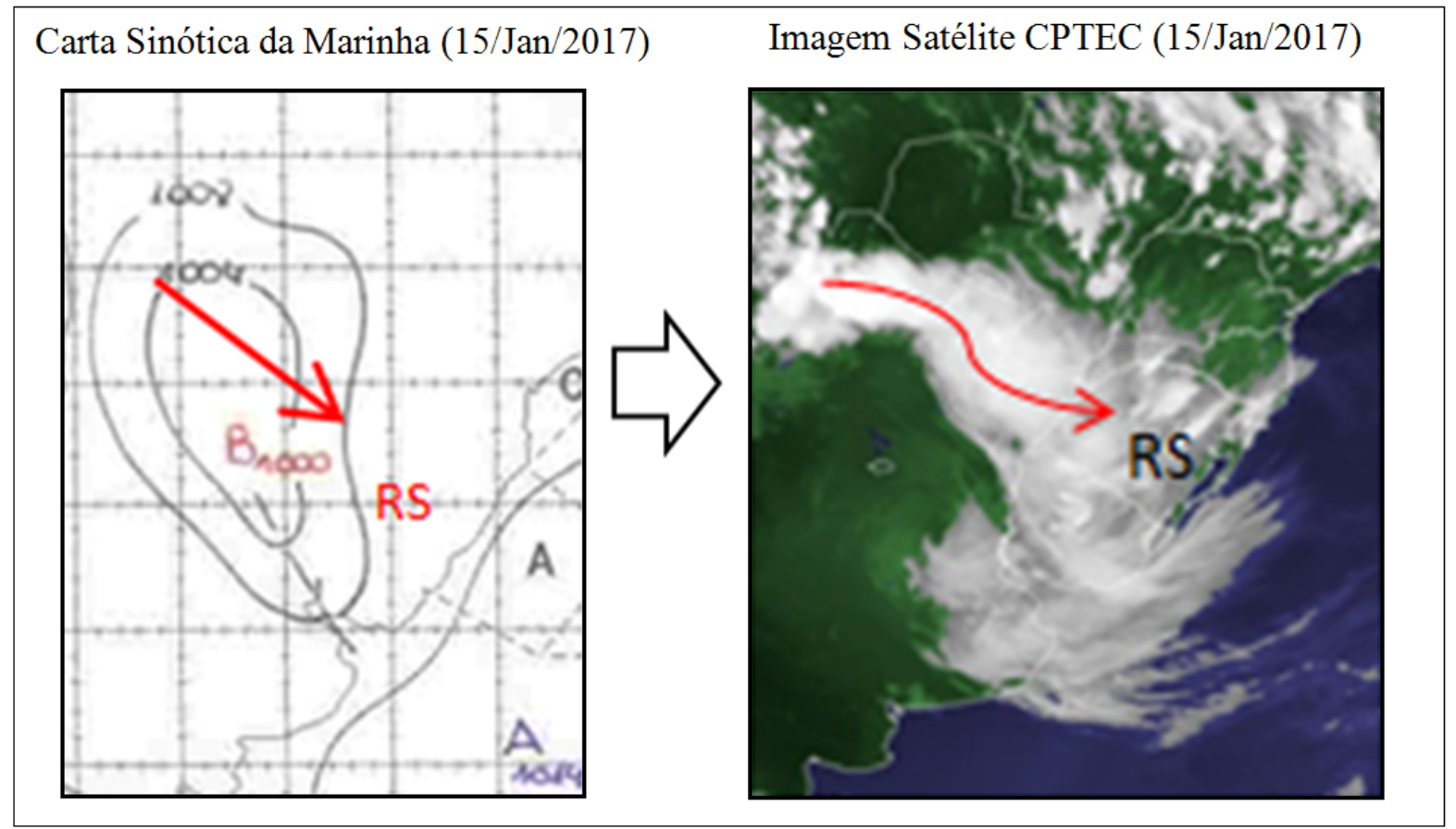

Figura 7 - Representação da Baixa do Chaco (BC), sistema atmosférico atuante no $1^{\circ}$ caso. Fonte: CPTEC/INPE, Serviço Meteorológico da Marinha. Org: Duarte, V. A. 2017.

Com o domínio do sistema de baixa pressão sobre o estado do RS, consequentemente, sendo o causador dos estragos na lavoura deste produtor e em outras áreas onde pode ter sido atingida, nas setas em cor vermelha mostra a direção da massa de ar, este sistema sempre atinge o RS neste sentido e direção. Segundo Cunha (1997) este sistema de baixa pressão é muito comum no Estado do rio Grande do Sul, com maior intensidade no verão, como é uma onda de calor, quente e úmida chega ao RS com bastante intensidade e a característica principal causada por desse sistema, além da sensação de abafamento, as chuvas na maioria das vezes são acompanhadas de granizo, que foi o que aconteceu naquele dia 15 de janeiro de 2017 na bacia do Alto Jacuí. 
4.2. Adversidade climática em 19 de Dezembro de 2010.

Este segundo caso ocorreu no dia 19 de Dezembro de 2010. A notícia foi divulgada pela Rádio Gazeta da Serra onde, naquele domingo, uma chuva de granizo que durou cerca de 15 minutos que foi o suficiente para causar prejuízos para cerca de 600 produtores de tabaco dos municípios de Passa Sete, Lagoa Bonita do Sul, Tunas e Lagoão. Conforme o gerente da Afubra na época, João Paulo, até a quarta feira daquela semana cerca de 500 produtores segurados da Afubra entraram em contato com a empresa para informarem o ocorrido. As localidades de Murta, Campo de Sobradinho e Pitingal foram as mais atingidas pelo granizo, conforme mostra na (Figura 7) a lavoura de um produtor que teve sua lavoura bastante destruída pela precipitação de granizo.

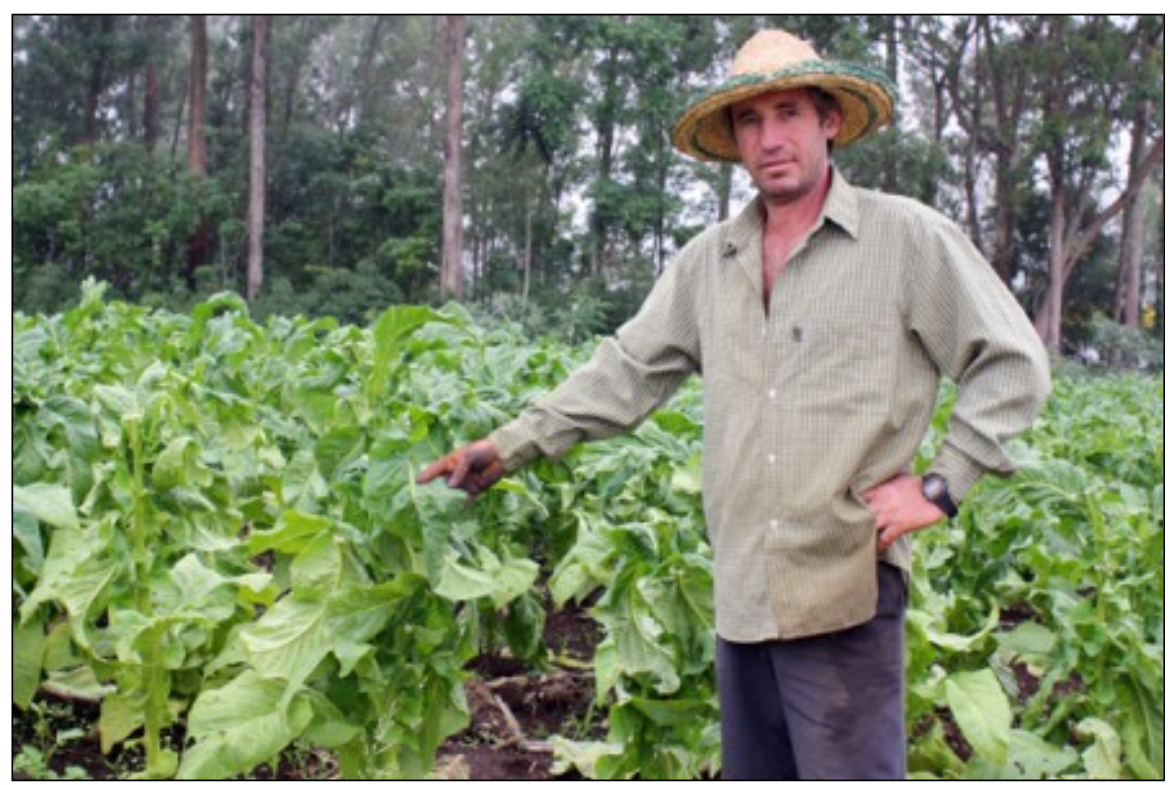

Figura 8 - Prejuízo na cultura do tabaco em Passa Sete, Lagoa Bonita do Sul, Tunas e Lagoão.

Fonte:Gazeta da Serra/ Luiz Fernando dos Santos.

De acordo com produtor José Delmar Rech (foto), 43 anos, morador de Pitingal Passa Sete, teve $80 \%$ da produção de fumo das lavouras da família danificadas pelo granizo. Ele disse na entrevista que "Dos 60 mil pés de tabaco que foram plantados, pouca coisa pode ser aproveitada" disse. Seu irmão, Luiz Adelmo Rech, também morador da localidade, teve um prejuízo menor, dos 190 mil pés de tabaco plantados 30\% foram atingidos.

A carta sinótica e a imagem de satélite do CPTEC/INPE do dia 19 de Dezembro de 2010 também estava sob domínio de do sistema de baixa pressão vindo do Chaco, e foi o que ocasionou uma grande quantidade de lavouras atingidas no Estado com muita intensidade na bacia hidrográfica do Alto Jacuí e arredores como mostra na (figura 9) a situação atmosférica daquele dia, com a massa de ar totalmente sobre o estado como mostra a indicação da seta em vermelho. 


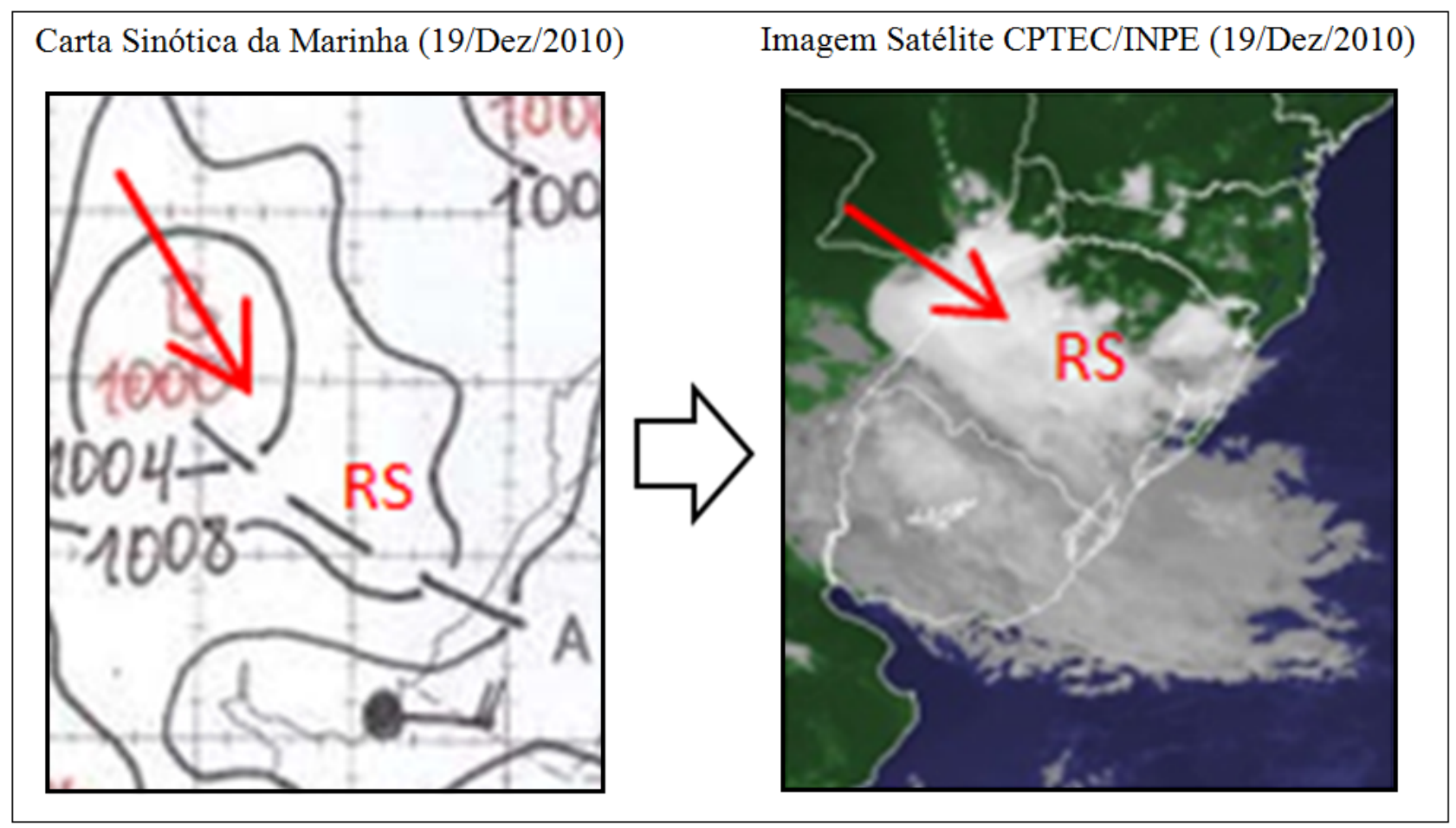

Figura 9 - Representação da Baixa do Chaco (BC), Sistema atmosférico atuante.

Fonte: CPTEC/INPE, Serviço Meteorológico da Marinha. Org: Duarte, V. A. 2017

A precipitação de granizo acontece de forma localizada, atingindo pequenas áreas isoladas, e o prejuízo de forma direta acontece com o impacto das pedras de gelo sobre as lavouras, causando significativa perda de quantidade e qualidade. Visto que a cada ano há ocorrências de temporal nesta região e nesta época, é muito recorrente, principalmente na fase em que o tabaco está no seu ciclo mais avançado no caso, quando o produto está pronto para ser colhido. É a fase mais suscetível a ocorrência de perda de produto por causa do clima.

Dessa forma, na entrevista realizada com a meteorologista Taciana Weber de Menezes ela aborda que "Segundo a EMBRAPA (Empresa Brasileira de Pesquisa Agropecuária) a região do Brasil onde a ocorrência desse fenômeno é mais comum é a porção centro-sul do país. O Sul do país por ser uma região influenciada por diferentes tipos de sistemas meteorológicos, tais como SCM's (Sistemas Convectivos de Mesoescala), CCM's (Complexos Convectivos de Mesoescala) que abrangem milhares de quilômetros e também por ser uma região frontogenética, ou seja, favorável á formação de frentes frias, todos esses fenômenos são susceptíveis a formação do granizo e a época com maior ocorrência desse fenômeno são meses de primavera”. Com essa fala da meteorologista, é possível ter noção de que estes eventos ganham força quando se aproxima o verão, e por azar dos produtores, neste período o tabaco está praticamente todo na lavoura, estando sujeito a ser atingido.

Com isso, ela também afirma que "o período do inverno para o verão são mais frequentes as formações de SCM's (Sistemas Convectivos de Mesoescala) e CCM's (Complexos Convectivos de Mesoescala) nessa época e esses fenômenos são favoráveis á formação do granizo". Assim, pode-se notar a quantidade de chuvas acompanhadas de granizo neste período, e isto para o tabaco é muito ruim pelo fato de a planta estar na lavoura. Neste período, entre inverno e primavera, é o instante em que a planta esta quase no seu período total de desenvolvimento, a planta já possui 
um porte grande o que facilita a sua quebra em caso de chuva com granizo, que segundo a afirmação da meteorologista é o período com maior incidência desse fenômeno.

Como a região sul e sudeste da bacia hidrográfica do Alto Jacuí é a região com maior numero de produtores de tabaco, está área apresenta relevos ondulosos com bastante declividade em alguns lugares, a região ao entorno e na própria bacia na parte mais ao sul é composta por vales o que poderia favorecer a formação de nuvens produtoras deste fenômeno na região. Então, segundo a meteorologista ela afirma que "nas regiões de vale tendem a serem mais protegidas do vento em condições normais o que acaba represando mais facilmente calor e umidade em tais regiões favorecendo a formação ou potencializando as tempestades associadas a esse tipo de nuvem". Portanto, o fato de a bacia hidrográfica do Alto Jacuí estar nessa parte de transição da depressão central para o planalto, a presença dos vales podem sim contribuir para á ocorrência de chuvas com granizo.

Dessa forma, estas contribuições da meteorologista coincidem muito com as respostas dos produtores no questionário que foi aplicado. Segundo os produtores entrevistados, quando fizeram uma análise da interferência climática no cultivo do tabaco, as respostas foram às mesmas, que a temperatura prejudicava a planta no verão. A chuva tinha seus pontos positivos e negativos, quando a chuva ocorria de acordo com a necessidade da planta, era uma coisa boa, mas em muitos casos a chuva era em grande quantidade ou com a presença de granizo poderia causar grandes prejuízos na lavoura. Os ventos quando muito forte também poderia causar estragos, chegando até a arrancar os pés de tabaco em alguns casos, e a geada, age de forma negativa somente no período de transplante para a lavoura, caso houvesse uma geada muito forte sobre a planta recém transplantada poderia haver perdas.

Outro ponto interessante do questionário era se os produtores entrevistados já haviam perdido tabaco em função de temporais, geadas, dentre outros. Os dois produtores confirmaram que já haviam perdido grande parte da produção em outros anos, principalmente pelo granizo, o produtor de Arroio do Tigre Vitélio Raminelli relatou que já tiveram casos com perda de $90 \%$ da produção em função do granizo, conforme o levantamento feito por um representante da Afubra.

\section{Conclusões}

Portanto, pode-se perceber que a influência do clima na agricultura é um tema importante, de forma que conhecer as particularidades de cada espécie e também as condições geográficas do ambiente é algo necessário para o bom desempenho do setor agrário na economia. Assim, é evidente que períodos de seca extrema ou de severas anomalias climáticas podem prejudicar a produção e todas as atividades socioeconômicas dela dependentes. Existe uma ampla relação entre clima e produção de tabaco, pois acontece que as práticas agrícolas são extremamente dependentes das variações atmosféricas, o que quer dizer que alguns fatores, como a quantidade de chuvas, a temperatura e outros elementos, interferem na produção das lavouras, tanto de forma positiva quanto negativa.

Sendo assim, o tabaco é mais propício de ser cultivado em regiões que apresentam os tipos climáticos mais adequados para a sua manutenção. Apesar disso, com o passar do tempo estão se desenvolvendo técnicas para diminuir esses efeitos e facilitando o seu manuseio. Então, para se alcançar produtividade econômica alta, o tabaco necessita de condições favoráveis durante todo o seu ciclo vegetativo, isto é, exigem determinados limites de temperatura nas várias fases do ciclo, de uma quantidade mínima de água, e de um período seco nas fases de maturação e colheita. Caso o clima não colabore, a produtividade e qualidade do tabaco já sofre influência. 


\section{Agradecimentos}

O presente trabalho foi realizado com apoio do Programa Nacional de Cooperação Acadêmica da Coordenação de Aperfeiçoamento de Pessoal de Nível Superior-CAPES/Brasil- No Processo: 88881.068465/2014/01 - Projeto N ${ }^{\circ}$ 071/2013 CAPES/PROCAD.

\section{Referências}

AFUBRA. Associação dos Fumicultores do Brasil. Disponível em: <http://www.afubra.com.br/fumicultura-brasil. html> Acesso em: 28 abr. 2017.

ANTONELLI. V. Erosão de Solos sob o Cultivo do Tabaco (nicotina tabacun) em uma Pequena Propriedade Rural no Município de Irati Paraná. Caminhos de Geografia. v. 11, n. 36, p. 150 - 167, dez. 2010.

AYOADE, J. O. Introdução à Climatologia para os Trópicos. 10. ed. Rio de Janeiro: Bertrand Brasil, 2004.

BOIEIRO, M. Tabaco. Portugal, 2008. Disponível em: <http://institutohipocratesonline.com/index.php/medicinasnao-convencionais/fitoterapia/192-tabaco.html>Acesso em: 3 abr. 2017.

CPTEC. Centro de Previsão de Tempo e Estudos Climáticos. Disponível em: < http://satelite.cptec.inpe.br/home/ index.jsp> Acesso em: 12 Jun. 2017.

CUNHA, G. R. Meteorologia Fatos e Mitos. 1. ed. Passo Fundo/RS: Embrapa, 1997

EMBRAPA. Empresa Brasileira de Pesquisa Agropecuária. Disponível em: https://sistemasdeproducao.cnptia. embrapa.br/FontesHTML/Uva/UvaAmericanaHibridaClimaTemperado/clima.htm> Acesso em: 8 abr. 2017

PROFIGEN. Profigen do Brasil Ltda. Disponível em: <http://www.profigen.com.br/ler/1/349/315/cura> Acesso em: 20 jan. 2017.

P.M.I Philip Morris International. Disponível em:<http://www.pmi.com/pt_pt/our_products/growing_tobacco/pages/ growing_tobacco.aspx> Acesso em: 23 mar. 2017.

RÁDIO GAZETA. Grupo Gazeta da Serra. Disponível em: < http://www.grupogaz.com.br/gazetadaserra/ noticia/254197granizo_causa_prejuizos_em_lavouras_de_fumo/edicao:2010-12-17.html>Acesso em: 27 abr. 2017

RÁDIOS SOBRADINHO. Rádio Jacuí FM e AM. Disponível em: <http://www.radiosobradinho.com.br/site/ granizo-causa-estragos-em-pelo-menos-200-lavouras-do-centro-serra/> Acesso em: 25 abr. 2017.

REDIN, E. A Dinâmica do Tabaco no Território Centro Serra - Rio Grande do Sul, Brasil. Revista de Biologia e Ciências da Terra. V. 13, n 1, p. 21-27, 2013.

SARTORI, M. G. B. A dinâmica do clima do Rio Grande do Sul: indução empírica e conhecimento científico. São Paulo: Terra Livre, 2003.

SEMA- Secretaria Estadual do Meio Ambiente. Bacia Hidrográfica do Alto Jacuí. Disponível em: < http://www. sema.rs.gov.br/bacias-hidrograficas> Acesso em: 30 jun. 2017.

SINDITABACO. Sindicato Interestadual da Indústria do Tabaco. Disponível em: $<$ http://sinditabaco.com.br $>$ Acesso em: 28 abr. 2017

ZIANI. P. Caracterização Geográfica da Bacia Hidrográfica do Alto Jacuí: Subsídio ao Manejo Integrado. Trabalho de Conclusão de Curso (Licenciatura Plena em Geografia) Universidade Federal de Santa Maria. 2014. 67p. 